\title{
SUSCETIBILIDADE DE ROEDORES SILVESTRES DE ÁREAS NÃO PESTOSAS À PASTEURELLA PESTIS.
}

\author{
Dalva A. Mello :
}

\begin{abstract}
O autor estudou roedores silvestres provenientes de uma área não pes. tosa no Estado de Pernambuco quanto à susceptibilidade em relacão a Pasteurella pestis. Os resultados obtidos mostraram que os animais são suscetiveis ao germe.
\end{abstract}

\section{INTRODUÇ̃̃O}

A peste no Brasil se encontra atualmente confinada às zonas rurais. A sua conservação e transmissão estão confiadas a espécies de roedores silvestres sendo poderosamente influenciados por fatores climáticos, nos quais se busca com freqüência explicação (4).

Várias espécies de roedores silvestres têm sido encontradas freqüentemente infectadas pela equipe de Dr. M. Baltazard em Exú-Pernambuco (2). Estas espécies que estão implicadas na transmissão de $P$. pestis não têm sua distribuição limitada sòmente aos focos pestosos como é o caso de Zygodontomys pixuna, de Oryzomys eliurus e de Oryzomys subflavus (9).

Do ponto de vista epidemiológico é importante o conhecimento da susceptibili-dade à $P$. pestis de roedores silvestres, não só de áreas pestosas como também de áreas não pestosas.

Considerando o problema exposto acima, o autor do presente trabalho resolveu estudar a susceptibilidade de roedores silvestres provenientes de áreas não pestosas à Pasteurella pestis, como anteriormente havia feito em relação a roedores domésticos da cidade de Recife (7).

\section{MATERIAL E MÉTODOS}

O trabalho foi iniciado no mês de setembro de 1967 e concluído no mês de marçc de 1969 .

1. Roedores - Foram utilizados roedores silvestres provenientes da Zona de Mata Úmida do município São Lourenço, Estado de Pernambuco, área onde nunca foi registrado qualquer caso de peste.

Foram experimentados 157 animais das seguintes espécies: $55 \mathrm{Zy}$ godontomys pixuna, 45 oryzomys eliurus, 20 Oryzomys subflavus, 15 Cercomys cunicularius laurentius $\mathrm{e}$ 12 Akodon arviculoides cursor.

Os animais capturados eram desinfestados das pulgas e ficavam no laboratório, em quarentena, antes de ser inoculados.

Para comparação dos resultados foram utilizados camundongos albinos da cêpa "Swiss" de idade 3-4 meses, mantidos no biotério do Centro de Pesquisas Aggeu Magalhães.

2. Amostras de $P$. pestis utilizadas

* Biologista do Centro de Pesquisas Aggeu Magalnães (I.N.E.Ru.). Enderêço atuel: IBTM Caixa Postal 1859, Rio, Guanabara. 
--Duas amostras de $P$. pestis foram empregadas: uma, chamada PEXU 19, isolada por Dr. M. Bahmanyar (Perito em peste do Instituto Pasteur do Iran) de um roedor silvestre $O$. subflavus proveniente do município de Exú, Estadc de Per-nambuco, em 19-1-1967; e outra, chamada RANGEL, deada por Dr. A. Bica (OPAS) isolada em 1960, também de um roedor silvestre Sigmodon hispidus em Camp. RANGEL, Venezuela. Ambas as amostras haviam sido estudadas anteriormente quanto à sua virulência por Mello em 1968 (8). riou de 1.250 a 39,4 para os roedores silvestres e de 7.500.000 a 0,75 para os camundongos. Para a determinação da DL50 foram feitas de 4 a 6 dosagens pcr espécie animal.

Os animais inoculados que não morriam nos primeiros dias ficavam em observação até o vigésimo dia, quando eram sacrificados. Bacterioscopias do fígado, pulmão, baço e sangue do coração foram realizadas para se certificar de infecçāo pestosa.

O cálculo da LD50 foi feito pelo méto do de Litchfield \& Wilcoxon (6).

\section{TABELA I}

Susceptibilidade de Roedores Silvestres Comparada à de Camundongos de idade 3-4 meses da Cêpa "Swiss" à Pasteurella pestis.

\begin{tabular}{l|crr}
\hline \multicolumn{1}{c|}{ Roedores } & $\begin{array}{c}\text { Amostras de } \\
\text { P. Pestis }\end{array}$ & DL50 & Limites de Confiança \\
\hline Z. pixuna & PEXU 19 & 12 & $24-6$ \\
O. eliurus & PEXU 19 & 90 & $216-39$ \\
O. subflavus & PEXU 19 & 165 & $330-82,5$ \\
Z. pixuna & RANGEL & 250 & $500-125$ \\
O. eliurus & RANGEL & 120 & $312-50$ \\
Camundongo & PEXU 19 & 0,46 & $\mathbf{0 , 5 0 - 0 , 4 0}$ \\
Camundongc & RANGEL & 1.400 & $5.600--350$ \\
\hline
\end{tabular}

As culturas, reisoladas em placas de agar simples, eram semeadas em água peptcnada e incubadas à $37^{\circ} \mathrm{C}$. Após 24 horas de incubaçāo eram retiradas da estufa para contagem das bactérias feita na câmara de Neubauer, com o corante azul de Loeffler. As culturas eram mantidas, no perícdo das inoculações, numa caixa de gêlo.

3. Inoculações. - A técnica escolhida para as inoculaçōes foi a subcutânea. Os roedores fcram distribuidos em grupos de 5 para cada dosagem. O número de germes inoculados va-

\section{RESULTADOS}

Os resultados que puderam ser calculados em LD50 para a susceptibilidade encontram-se na tabela 1 .

Não foi possivel, pelo pequeno número de animais das espécies Cercomys cunicularius laurentius e Akodon arviculoides cursor, o cálculo da LD50 para tôdas as amostras. Os 15 C.c. laurentius e os $12 A$. a. cursor foram inoculados apenas com a amostra PEXU-19 sendo cs seus resultados apresentados em percentuais na tabe la II. Tóda bacterioscopia realizada mos-

\section{TABEIA II}

Percentual de Mortos de Duas Espécies de Roedores Silvestres Inoculados Com Amostras de $P$. pestis PEXU 19.

\begin{tabular}{|c|c|c|c|c|c|c|c|c|}
\hline \multirow{2}{*}{$\begin{array}{l}\text { DOSES } \\
\text { ROEDORES }\end{array}$} & \multicolumn{2}{|c|}{625} & \multicolumn{2}{|c|}{312,5} & \multicolumn{2}{|c|}{156,2} & \multicolumn{2}{|c|}{78,1} \\
\hline & $\mathbf{N}$ & $\%$ & $\mathrm{~N}^{\prime}$ & $\%$ & $\mathbf{N}^{\circ}$ & $\%$ & $\mathbf{N}^{\prime}$ & $\%$ \\
\hline C.c. iaurentius & 5 & 100 & 5 & 100 & 5 & 80 & -- & $\ldots$ \\
\hline A.a. cursor & $\ldots$ & $-\ldots$ & 5 & 100 & 5 & 80 & 2 & 100 \\
\hline
\end{tabular}


trou com grande nitidez a abundância de pasteurelas.

\section{CONCLUSÓES E COMENTÁRIOS}

Analisando os resultados obtidos para LD50 das espécies de roedores silvestres aqui utilizados e considerando o conceito de Holdendried \& cols. (5) conclui-se que êstes animais podem ser considerados como susceptíveis à infecção com $P$. pestis.

Observando os dados da tabela II, embora não se possa aplicar o mesmo conceito acima citado, é possível verificar entretanto, que a LD50 da amostra PEXU-19 está em tôrno de 312,5 germes quer seja para C.c. laurentius, quer para A.a. cursor. Já a dose que mata $80 \%$ das duas espécies está perto das LD50 calculadas pa- ra Z.pixuna e O. eliurus com esta mesma amostra.

Pouco se conhece sôbre a susceptibilida. de de rcedores brasileiros a $P$. pestis $(1,10)$. Torna-se, assim, difícil de julgar a importância epidemiológica que a maior ou menor susceptibilidade dos roedores possa ter em relação à manutenção da peste $\mathrm{em}$ determinadas regiões. Não há dúvida no entanto de que a peste nāo poderia existir em áreas cnde os roedores fôssem totalmente resistentes à infecção. A presença de roedores susceptiveis é, assim, um dos fatores capazies de entreter a epizootia. A êste propósito vale mencionar os trabalhos feitos no Irã e na Rússia sôbre o fenômenc da resistência específica de roedores silvestres, sua importância na manutenção da doença e transmissão às espécies susceptíveis (3).

\section{SUMMARY}

The susceptibility of wild rodents to the infection with Pasteurella pestis is studied. The rodents were originated from a non-endemic area in the State of Pernambuco-Brazil. All the rodents were considered susceptible to the infection.

\section{BIBLIOGRAFIA}

1. BAHMANYAR, $\mathbf{M}$. - Recherches sur l'epidemiolcgie de la peste au Brésil. Eight International Congresses on Tropical Medicine and Malaria. Teheran - Iran. Abstracts and Reviews - 551-553, 1968.

2. BAHMANYAR, M. - Informação pessoal. 1967.

3. BALTAZARD, M. - The conservation of plague in inveterate foci. J. Hyg. Epidem. Microbiol. \& Immunol., 8: 409-421, 1964.

4. BARRERA, J. M. - Relatóric sôbre a peste no Brasil. Brasil 1-30, HCO: 774: 80,1960 .

5. HOLDENDRIED, R., and QUAN, S. F. - Susceptibility of New Mexico ro. dents to experimental plague. Publ. Health Rep., 71: 979-984, 1965.

6. LITCHFIELD, J. T. \& WILCOXON, F. - A simplified method of evalua- ting dose effect experiments. J. Pharmacol. \& Exp. Therap. 96: 99. $113,1949$.

7. MELLO, D. A. - Susceptibilite de Rattus norvegicus et Rattus raltus frugivurus de la ville de Recife à la Pasteurella pestis. Rev. Soc. Bras. Med. Trop. 2: 127-132, 1968.

8. MELLO, D. A. - Virulence des souches aie Pasteurella pestis isolées en Pernambuco (Brésil). Rev. Inst. Med. Trop. São Paulo. 11: 111-114, 1969.

9. MELLO, D. A. -- Dades em publicacão.

10. SIMON, R. - Verificação da sensibí lidade dos roedores da Região Neotrópica. Monografias do Serviço Nacional de Peste. Gráfica Debret. Rio de Janeiro. Brasil, 1951 . 